\title{
Genetic variability assessment in bread wheat (Triticum aestivum) grown in Algeria using microsatellites SSR markers
}

\author{
KARIMA KARA ${ }^{1}$, MALIKA RACHED-KANOUNI ${ }^{2}$, SAMAH MNASRI ${ }^{3}$, HICHEM KHAMMAR ${ }^{2, \bullet}$, \\ M'BAREK BEN NACEUR ${ }^{3}$ \\ ${ }^{1}$ Department of Biology and Plant Ecology, Faculty of Natural and Life Sciences Université des Frères Mentouri Constantine 1. BP, 325 Ain el Bey \\ Road, 25017, Algeria \\ ${ }^{2}$ Laboratory of Functional Ecology and Environment, Department of Life and Nature Sciences, Faculty of Exact Sciences and Life and Nature Sciences, \\ University of "Larbi Ben M'hidi", Oum El Bouaghi. 1 November 1954 Street, Oum El Bouaghi 04000. Algeria. "email: Khammar.eco.env@gmail.com \\ ${ }^{3}$ National Gene Bank of Tunisia. Yasser Arafat Street, 1080, Tunis, Tunisia
}

Manuscript received: 5 April 2020. Revision accepted: 17 May 2020.

\begin{abstract}
Kara K, Rached-Kanouni M, Mnasri S, Khammar H, Ben Naceur MB. 2020. Genetic variability assessment in bread wheat (Triticum aestivum) grown in Algeria using microsatellites SSR markers. Biodiversitas 21: 2638-2644. The assessment of genetic diversity is a key step in evaluating the adaptation of populations to new environmental conditions, and thus in the selection of new cultivars. The present investigation aimed to assess genetic variability of bread wheat (Triticum aestivum L.) genotypes grown in Algeria. The 17 hexaploid genotypes of bread wheat were assessed using 16 molecular microsatellites of SSR (Simple Sequence Repeat). Among the 16 microsatellite markers tested, only 11 markers were the most polymorphic and reproducible. The Polymorphism Information Content (PIC) values per locus varied from 0.14 to 0.70 with an average of 0.48 and 0.49 . Genetic similarity between genotypes varied from 0.27 and 0.92 with an average of 0.60 . The highest genetic distance value of 0.92 has been scored between Kauz/Pastor/Fiscal and Wbll1*2/Brambling. The lowest value of 0.27 has been scored between Cham6 and Pastor/Wbll1. Genetic similarity was calculated by molecular derived data and used to produce a dendrogram. The genotypes were grouped in two clear clusters according to their origin and pedigree. The first cluster included wheat genotypes Ain Abid (local genotypes), Attila/2 Pastor, and 5119 (introduced genotypes). The second group revealed high polymorphism and was subdivided into four sub-groups. This high level of diversity revealed among the accessions of wheat, grown in Algeria could be used in breeding programs.
\end{abstract}

Keywords: Bread wheat, genetic diversity, microsatellites, PIC, Triticum aestivum

\section{INTRODUCTION}

Bread wheat (Triticum aestivum L.) has a total production of more than 600 million tons per year (Bellatreche et al. 2017). It is one of the richest crops in protein and calories (Azzam and Abd El-Kader 2010; Flagella et al. 2010; Grassini et al. 2013). Nevertheless, despite explosive growth during the recent 40 years, the annual growth in wheat production has begun to decrease or even stagnate for most countries in the world (Paux et al. 2012). World population growth requires a steady increase in wheat production. Increasing genetic diversity for economically important traits is one of the objectives of the main tasks of wheat genetics and breeding (Gultyaeva 2012).

However, the Algerian wheat production remains very relatively low and unstable from one year to another. Thus, wheat production in the 2017/2018 season was 3.1 million tons against 1.99 million tons in the previous season. However, wheat production recorded a yield of 3.9 million tons of wheat in the 2018/2019 season. This unstable production mainly due to very variable and often unfavorable climatic conditions, such as irregular rainfall, diseases, drought (Allahverdiyev 2015; Toklu et al. 2015; Bellatreche et al. 2017; Ozlem and Begum 2018). This leads to significant variations in production and yield. Wheat productivity is reduced due to a variety of changing climatic events, which affect global food security (Mickelbart et al. 2015; Toklu et al. 2015). Thus, the lack of rainfall and the poor distribution of rainfall during the year largely explain the large variation in cereal production (Boudour et al. 2011; Kara and Brinis 2012).

On the world market, Algeria is among the main importers of wheat (with $65 \%$ of the African market) due to the low capacity of the national sector to meet the growing consumption needs of the population (Boudour et al. 2011; Kara and Brinis 2012). Bread wheat and durum wheat (Triticum durum Desf.) are the main staple diet for consumers in this country, local cereal production covers only a little more than $30 \%$ of the country's needs. The average area consecrated to wheat in Algeria is about 1.9 million ha, but with a low yield $18 \mathrm{qx} /$ ha of durum wheat and 17qx/ha of common wheat (CIC 2010). However, the area destined for the cereal crop in Algeria is around 3 million ha (FAOSTAT 2014). About $60 \%$ of the cereal-growing areas are on a semi-arid climate, in areas where farmers traditionally use a limited amount of inputs (seeds, fertilizers), resulting in low production, in fact, in regions where annual precipitation, mostly in winter, is less than $450 \mathrm{~mm}$ on average (Sahnoune et al. 2013; Merouche et al. 2014).

The variation in bread wheat yields in semi-arid areas such as Algeria is largely due to the effects of water and 
heat stress (Farzad et al. 2013; Kara et al. 2014; Yao et al. 2014; Aissaoui and Fenni 2018). In response to this situation, various improvement strategies are being considered. Identifying genetic variation is essential for the effective management and use of genetic resources (Tahir 2010). Several markers suitable for genetic diversity studies have been identified, as developed in recent years. Several markers suitable for genetic diversity studies have been identified, as developed in the last few years. The emergence of new PCR-based molecular markers, such as microsatellites or simple sequence repeat (SSRs) and Single Nucleotide Polymorphism (SNPs) has created the opportunity to characterize collections of germplasm that were previously impossible to collect and initiate the productive wheat breeding program (Drikvand et al. 2013; Reza et al. 2015; Allen et al. 2017). Microsatellites have a high potential use for the genetic analysis because of their high degree of polymorphism and they are co-dominantly inherited (Huang et al. 2002; Ali et al. 2008; Reza et al. 2015).

Microsatellites are useful in genetic characterization of drought tolerance in bread wheat (Ateş Sönmezoğlu and Terzi 2018) and have a great potential use for the genetic analysis because of their high level of polymorphism and they are co-dominantly inherited (Tahir 2010; Ateş Sönmezoğlu et al. 2012; Reza et al. 2015; Tomar et al. 2016; Zarei Abbasabbad et al. 2016). The objectives of this study were to (i) use SSRs to assess levels and patterns of genetic variability among a representative sample of local wheat genotypes, (ii) compare these genetic diversity estimates with other international wheat cultivars, (iii) and use wheat microsatellite markers for the characterization and assessment of the genetic diversity of seventeen of local and introduce bread wheat genotypes.

\section{MATERIALS AND METHODS}

\section{Plant materials}

This investigation was carried out at the experimental farm of ITGC (Technical Institute of High Culture) in Constantine/Algeria. In this investigation, three local genotypes and fourteen introduced genotypes were represented in Table 1.

The genotypes were sown and grown in the ITGC experimental field in a complete randomized block model with two replicates per genotype. Each genotype was sown along 2 m-long rows at a density of 40 seeds per line with 5 $\mathrm{cm}$ between seeds.

\section{DNA isolation and amplification}

The extraction of total DNA was performed from frozen and freshly harvested young leaves using a modified CTAB method described by Ben Naceur (1998). Using this protocol, a consistent yield of good quality DNA fragments was achieved with a minimum of $20 \mu \mathrm{g}$ DNA/g leaves. The DNA was purified by RNase $(10 \mu \mathrm{g} / \mathrm{ml})$ treatment and phenolic extraction. The concentration of purified DNA was estimated at $0.8 \%$ agarose gel. DNA was dissolved and preserved in TE buffers.

Table 1. Origin and pedigree of the genotypes studied

\begin{tabular}{llll}
\hline \multicolumn{1}{c}{ Nenotypes } & \multicolumn{1}{c}{ Pedigrees } & Origin \\
\hline & & & \\
V1 & Ain abid & ITGC/Algeria & Algeria \\
V2 & Arz & ITGC/Algeria & Algeria \\
V3 & Hidhab & ITGC/Algeria & Algeria \\
V4 & Hamam 1 & ICW92-0455-1AP-1AP-2AP-3AP-0AP & ICARDA/Syria \\
V5 & 5119 & & SERASENE/France \\
V6 & Milan/S87230/babax & CMSS97MO-3687T6040Y-03M-020Y-030M-015Y-38M & CIMMYT/Mexico \\
V7 & Angi-4 & ICW92-0326-12AP-1AP-2AP-3AP-0AP & ICARDA/Syria \\
V8 & Cham 6 & CM39992-8 M-7Y-OM-0AP & CIMMYT/Mexico \\
V9 & Attila & CM85-836-50 Y-0M-OY-3M-0Y & CIMMYT/Mexico \\
V10 & Attila/2 Pastor & CGSS97Y00042M-099T0PB-058Y-099M-099Y-099B & CIMMYT/Mexico \\
V11 & Pastor/Wbll1 & CMSA00Y00586-0POY 040M 040 SY-030M-17ZT & CIMMYT (Mexico) \\
V12 & Babax/Lr42//Babax*2/3vivitsi & CGSS01B00046T-099Y-099M-099M-099Y-21Y-0B & CIMMYT (Mexico) \\
V13 & Wbll1*2/Brambling & CGSS01B00062T-099Y 099M-099M-099Y-099M-77Y-0B & CIMMYT (Mexico) \\
V14 & Thelin//2*Attila*2/Pastor & CGSS02Y00089T-099B-099M-099Y-099M-4Y-0B & CIMMYT (Mexico) \\
V15 & Kauz/Pastor/Fiscal & CMSS02M00325S-030M-15Y-0M-0Y & CIMMYT (Mexico) \\
V16 & Prl/2*Pastor & CGSS97Y00034M099T0PB-027Y-099M-099Y-099M & CIMMYT (Mexico) \\
V17 & Babax/Lr42//Babax*2/3/Kukuna & CGSS01B00048T-099Y-099M-099M-099Y-099M-31Y-0B & CIMMYT (Mexico) \\
& & & \\
\hline
\end{tabular}


The amplification reaction was carried out in total reaction mixture of $25 \mu \mathrm{l}$ with two replications per reaction. The reaction mixture contains 50-100 ng of genomic DNA, $0.2 \mathrm{mM}$ dNTPs, $0.25 \mu \mathrm{M}$ of each primer, and $1 \mathrm{U}$ of Taq DNA polymerase (GoTaq, Promega) and its one-time concentrated buffer containing $1.5 \mathrm{mM} \mathrm{MgCl}_{2}$ The PCR amplification was performed with the following steps: one cycle of $94^{\circ} \mathrm{C}$ for $3 \mathrm{~min}, 35$ cycles of $2 \mathrm{~min}$ denaturing steps at $94{ }^{\circ} \mathrm{C}, 1 \mathrm{~min}$ annealing temperatures at $52-64^{\circ} \mathrm{C}$ (Table 2) depending on the primers, $2 \mathrm{~min}$ extension at $72{ }^{\circ} \mathrm{C}$ and followed by a final extension for $1 \mathrm{~min}$ at $72^{\circ} \mathrm{C}$. Electrophoresis of DNA chain polymerization amplification was performed on $2 \%$ agarose gel electrophoresis in 1x Tris-Borate-EDTA buffer ( $\mathrm{pH}$ 8.3). To better discern some fine bands, SSR products were also separated using $40 \%$ non-denaturing polyacrylamide gel electrophoresis in 1x TBE buffer. DNA Ladder (Promega) at 100bp was used as a molecular size standard.

\section{Microsatellites markers analysis}

The reaction of DNA amplification by PCR was performed with 16 microsatellite primer pairs, i.e. WMC
14, WMC15, WMC 16, WMC 17, WMC 18, WMC 19, WMC 20, WMC 21, WMC 22, WMC 23, WMC 24, WMC 25, WMC 27, WMC 48, WMC 50, and WMC 283 (Table 2). These primers selected from the international consortium WMC (Wheat Microsatellite Consortium). They are the most polymorphic and well-distributed markers on the genome of bread wheat.

Table 3. PIC values, allele number, and annealing temperature (Ta) generated by polymorphic primers

\begin{tabular}{lccc}
\hline \multicolumn{1}{r}{ Primer } & PIC & Ta $\left({ }^{\circ} \mathbf{C}\right)$ & Nb alleles \\
\hline WMC 14 & 0.67 & 58 & 5 \\
WMC 15 & 0.39 & 55 & 2 \\
WMC 17 & 0.70 & 54 & 5 \\
WMC 20 & 0.49 & 54 & 2 \\
WMC 21 & 0.14 & 55 & 2 \\
WMC 25 & 0.62 & 52 & 3 \\
WMC 27 & 0.67 & 55 & 4 \\
WMC 48 & 0.48 & 64 & 2 \\
WMC 50 & 0.70 & 60 & 5 \\
WMC 283 & 0.59 & 60.4 & 3 \\
\hline
\end{tabular}

Table 2. Description of tested SSR primers (http:www.wheat.pw.usda.gov/ggpages/SSR/WMC)

\begin{tabular}{|c|c|c|c|c|}
\hline Primer & Sequences & Motifs & $\begin{array}{c}\text { Chromosome } \\
\text { location }\end{array}$ & $\begin{array}{c}\text { Alleles size } \\
\text { (bp) }\end{array}$ \\
\hline WMC 14F & ACCCGTCACCGGTTTATGGATG & $(\mathrm{CT})(\mathrm{CA})$ & $7 \mathrm{D}$ & 239 \\
\hline WMC 14R & TCCACTTCAAGATGGAGGGCAG & & & \\
\hline WMC $15 \mathrm{~F}$ & AGTCCGATTCGGACTCCTCAG & $(\mathrm{CT})(\mathrm{CA})$ & $4 \mathrm{~A}$ & 295 \\
\hline WMC $15 R$ & GGACTAACCGAGGGTAGTTG & & & \\
\hline WMC $16 \mathrm{~F}$ & ACCGCCTGCATTCTCATCTAA & (CT) & $4 \mathrm{~B}$ & 165 \\
\hline WMC $16 \mathrm{R}$ & GTGGCGCCATGGTAGAGATTG & & & \\
\hline WMC $17 \mathrm{~F}$ & ACCTGCAAGAAATTAGGAAC & (CA) & $7 \mathrm{~A}-7 \mathrm{~B}$ & 182 \\
\hline WMC $17 \mathrm{R}$ & CTAGTGTTTCAAATATGTCGA & & & \\
\hline WMC $18 \mathrm{~F}$ & CTGGGGCTTGGATCACGTCATT & $(\mathrm{CA})(\mathrm{CT})$ & $2 \mathrm{D}$ & 237 \\
\hline WMC $18 \mathrm{R}$ & AGCCATGGACATGGTGTCCTTC & & & \\
\hline WMC $19 \mathrm{~F}$ & CTGACATGCGGCATTCACTTCC & (CA) & $1 \mathrm{~A}$ & 153 \\
\hline WMC $19 R$ & AGGCTTAGAACACACCGACACG & & & \\
\hline WMC $20 \mathrm{~F}$ & TTAAAAACACGCGGATCTTCTC & (CA) & $1 \mathrm{~A}$ & 119 \\
\hline WMC $20 \mathrm{R}$ & GTACTCACATATTTCTCGGTCT & & & \\
\hline WMC $21 \mathrm{~F}$ & CGCTGCCGTGTAACTCAAAATC & $(\mathrm{GA})_{37}$ & & 136 \\
\hline WMC $21 R$ & AGTTAATTGGGCGCTCCAAGAA & & - & \\
\hline WMC $22 \mathrm{~F}$ & ATCATTGGTTTCCTCTTCACTT & (GT) 24 & & 169 \\
\hline WMC $22 \mathrm{R}$ & GTGGACTATTTAACATCTTCAT & & - & \\
\hline WMC $23 \mathrm{~F}$ & ATTCGCTCATACGATAGGGTTG & CT) $22(\mathrm{CT})_{18}$ & & 314 \\
\hline WMC 23R & AGAGGCTGGTGTAGTTGGTTTG & & - & \\
\hline WMC 24F & GTGAGCAATTTTGATTATACTG & $(\mathrm{GT})_{28}$ & $1 \mathrm{~A}$ & $136-155$ \\
\hline WMC 24R & TACCCTGATGCTGTAATATGTG & & & \\
\hline WMC $25 \mathrm{~F}$ & TCTGGCCAGGATCAATATTACT & (GT) 26 & $2 \mathrm{~B}$ & 166 \\
\hline WMC 25R & TAAGATACATAGATCCAACACC & & & \\
\hline WMC $27 \mathrm{~F}$ & AATAGAAACAGGTCACCATCCG & (GT) 25 & $2 \mathrm{~B}-5 \mathrm{~B}$ & $352-398$ \\
\hline WMC 27R & TAGAGCTGGAGTAGGGCCAAAG & & & \\
\hline WMC 48F & GAGGGTTCTGAAATGTTTTGCC & $(\mathrm{GA}) 9$ & $4 \mathrm{~B}$ & $139-190$ \\
\hline WMC 48R & ACGTGCTAGGGAGGTATCTTGC & & & \\
\hline WMC 50F & CTGCCGTCAGGCCAGGCTCACA & $(\mathrm{GT})_{10}(\mathrm{GT})_{16}$ & $3 \mathrm{~A}$ & $219-236$ \\
\hline WMC 50R & CAACCAGCTAGCTGCCGCCGAA & & & \\
\hline WMC $283 \mathrm{~F}$ & CGTTGGCTGGGTTATATCATCT & $(\mathrm{CA})_{19}(\mathrm{CA})_{8}$ & $4 \mathrm{~A}$ & \\
\hline WMC 283R & GACCCGCGTGTAAGTGATAGGA & & & \\
\hline
\end{tabular}


The SSR profiles were transformed into a binary matrix where the presence of the generated band at a precise level is scored as 1 and its absence is scored as 0 . The similarity matrix was generated with NTSYS (Numerical Taxonomy and Multivariate Analysis) software pc-2.02j (Rohlf 1989). A dendrogram was drawn using the UPGMA (Unweighted Pair-Group Method using Arithmetic Averages) cluster analysis.

The PIC (Polymorphism Information Content), according to Nei and $\mathrm{Li}$ (1979), is calculated by the following formula:

$$
\mathrm{PIC}=1-\sum_{i=1}^{k} P i^{2}
$$

Where: $k$ is the total number of alleles detected for a locus of a marker $P i$ is the proportion of the population carrying the $i$ th alleles, scored for each locus.

\section{RESULTS AND DISCUSSION}

\section{Results}

In this study, eleven microsatellite markers for 11 loci were used to characterize and evaluate the genetic diversity of seventeen wheat genotypes (Table 3). Amplified microsatellite loci were analyzed for polymorphism using polyacrylamide gel electrophoresis and the result revealed that all the primer pairs detected polymorphisms among the wheat genotypes analyzed. A total of 35 alleles were detected. The maximum number of alleles was observed at WMC 14, WMC 17, and WMC 50 primers.

According to Nei's (1979), the similarity coefficient between genotypes was ranged from 0.27 and 0.92 with an average of 0.60 (Table 4 ). The similarity indices showed that the two most closely related genotypes were Kauz/Pastor/Fiscal and Wbll1*2/Brambling with the highest similarity index 0.92. Results indicating that they are genetically similar to each other. On the other hand, the two most distantly related genotypes were Cham6 and Pastor/Wbll1 with low similarity index 0.27.

A dendrogram was drawn using the UPGMA (Unweighted Pair-Group Method using Arithmetic Averages) cluster analysis among 17 genotypes of bread wheat (Figure 1).

\section{Discussion}

Of a total of 16 SSR primers tested, only 11 produced polymorphic bands (WMC 14, WMC 15, WMC 17, WMC 20, WMC 21, WMC 24, WMC 25, WMC 27, WMC 48, WMC 50, and WMC 283) (Table 3). No amplified products were obtained with WMC 16, WMC18, WMC 19, WMC 22 and WMC 23 primers. The Polymorphism Information Content (PIC) varied from 0.14 (WMC 21) to 0.70 (WMC 50 and WMC 17) with an average of 0.48 and 0.49 (Table 3 ). This indicates that the markers were highly informative. The PIC value $>0.5$ means the locus is considered as being a highly informative marker, whereas if the PIC value is $<0.25$, the locus is considered to be of low diversity (Nagy et al. 2012; Ramadugu et al. 2015). These results are confirmed in earlier studies on Moroccan wheat where the PIC values were between 0.29 and 0.79 (Zarkti et al. 2010). In another study, the PIC means value (0.30) for SSRs was lower than the mean value of 0.48 and 0.49 observed in the present study in Egyptian hexaploid bread wheat (Salem et al. 2014). In another recent study, Bellatreche et al. (2019) found that in the local bread wheat resources of the oases of Algeria, the information contained on polymorphism (PIC) shifted from 0 to 0.55 . However, these results are much higher in wheat Tunisian genotypes (PIC) from 0.33 to 0.94 respectively for WMC 25 and WMC 50 primers (Babay et al. 2015) varied from 0.25 to 0.89 with an average of 0.69 in Cameroonian bread wheat (Tékeu et al. 2017) and ranged from 0.7-0.89 with an average of 0.82 in Iranian wheat (Zarei Abbasabbad et al. 2016; Salehi et al. 2018).

Table 4. Similarity matrix for bread wheat genotypes based on 11 microsatellite markers

\begin{tabular}{|c|c|c|c|c|c|c|c|c|c|c|c|c|c|c|c|c|c|}
\hline & V1 & $\mathbf{V} 2$ & V3 & V4 & V5 & V6 & V7 & V8 & V9 & V10 & V11 & V12 & V13 & V14 & V15 & V16 & V17 \\
\hline V1 & 1.00 & & & & & & & & & & & & & & & & \\
\hline V2 & 0.61 & 1.00 & & & & & & & & & & & & & & & \\
\hline V3 & 0.56 & 0.45 & 1.00 & & & & & & & & & & & & & & \\
\hline V4 & 0.56 & 0.64 & 0.67 & 1.00 & & & & & & & & & & & & & \\
\hline V5 & 0.64 & 0.45 & 0.50 & 0.67 & 1.00 & & & & & & & & & & & & \\
\hline V6 & 0.50 & 0.38 & 0.70 & 0.52 & 0.61 & 1.00 & & & & & & & & & & & \\
\hline V7 & 0.58 & 0.48 & 0.70 & 0.61 & 0.70 & 0.91 & 1.00 & & & & & & & & & & \\
\hline V8 & 0.35 & 0.40 & 0.36 & 0.45 & 0.55 & 0.48 & 0.57 & 1.00 & & & & & & & & & \\
\hline V9 & 0.38 & 0.43 & 0.48 & 0.64 & 0.56 & 0.67 & 0.75 & 0.70 & 1.00 & & & & & & & & \\
\hline V10 & 0.72 & 0.55 & 0.50 & 0.33 & 0.67 & 0.61 & 0.70 & 0.55 & 0.48 & 1.00 & & & & & & & \\
\hline V11 & 0.48 & 0.73 & 0.50 & 0.67 & 0.50 & 0.43 & 0.52 & 0.27 & 0.56 & 0.42 & 1.00 & & & & & & \\
\hline V12 & 0.50 & 0.76 & 0.52 & 0.70 & 0.52 & 0.55 & 0.55 & 0.29 & 0.50 & 0.43 & 0.87 & 1.00 & & & & & \\
\hline V13 & 0.48 & 0.55 & 0.75 & 0.83 & 0.50 & 0.61 & 0.70 & 0.55 & 0.64 & 0.42 & 0.67 & 0.70 & 1.00 & & & & \\
\hline V14 & 0.56 & 0.45 & 0.83 & 0.83 & 0.67 & 0.70 & 0.78 & 0.45 & 0.64 & 0.50 & 0.50 & 0.52 & 0.83 & 1.00 & & & \\
\hline V15 & 0.56 & 0.64 & 0.75 & 0.83 & 0.50 & 0.61 & 0.70 & 0.64 & 0.64 & 0.50 & 0.58 & 0.61 & 0.92 & 0.83 & 1.00 & & \\
\hline V16 & 0.48 & 0.73 & 0.67 & 0.75 & 0.50 & 0.70 & 0.78 & 0.64 & 0.72 & 0.58 & 0.67 & 0.70 & 0.83 & 0.75 & 0.92 & 1.00 & \\
\hline V17 & 0.35 & 0.50 & 0.55 & 0.64 & 0.55 & 0.48 & 0.57 & 0.80 & 0.61 & 0.55 & 0.45 & 0.48 & 0.73 & 0.64 & 0.82 & 0.82 & 1.00 \\
\hline
\end{tabular}


The number of alleles detected by the primers ranged from 2 to 5 among the bread wheat genotypes. The most polymorphic of microsatellite markers was WMC 14, WMC 17, and WMC 50 primers with 5 alleles. The lowest numbers of alleles per locus were found in WMC 15, WMC 20, WMC 21, WMC 24, WMC 27, and WMC 48 primers with an average number of 3.2 alleles per locus. WMC 17 and WMC 50 primers had the highest number of alleles (5 alleles) per locus and the highest PIC value (0.70). The lowest number of alleles per locus and the PIC was calculated to be 2 and 0.14 respectively in WMC 21 (Table 3). Khaled et al (2015) found a high number of alleles per markers in Egyptian kinds of wheat, varied from 3 to 11 with an average of 5.59. In Omanian hexaploid landraces, bread wheat Al Khanjari et al. (2007) found an average number of 8.70 alleles per locus. Kondić-Špika et al. (2016) found a higher number of alleles per locus in Slovak bread wheat cultivars. The numbers were varied from 3 to 22, with an average of 7.8 alleles per locus. Leisova et al. (2007) showed that European wheat cultivars have an average of 12 alleles per locus. The same variation in alleles was also detected at other loci (Malik et al. 2013; Babay et al. 2015). However, Huang et al. (2002) used 26 microsatellites to study 998 accessions of bread wheat from 68 countries and have recorded an average of 18.1 alleles. Genetic diversity increases with the number of alleles at a given locus (Khaled et al. 2015). It was determined that primers with the highest number of alleles also had higher PIC values, results were confirmed by Ateş Sönmezoğlu and Terzi (2018).

Amplified microsatellite loci were revealed that all the primer pairs detected polymorphisms among the wheat genotypes analyzed. It has been detected a total of 35 alleles. The maximum number of alleles was observed at WMC 14, WMC 17, and WMC 50.

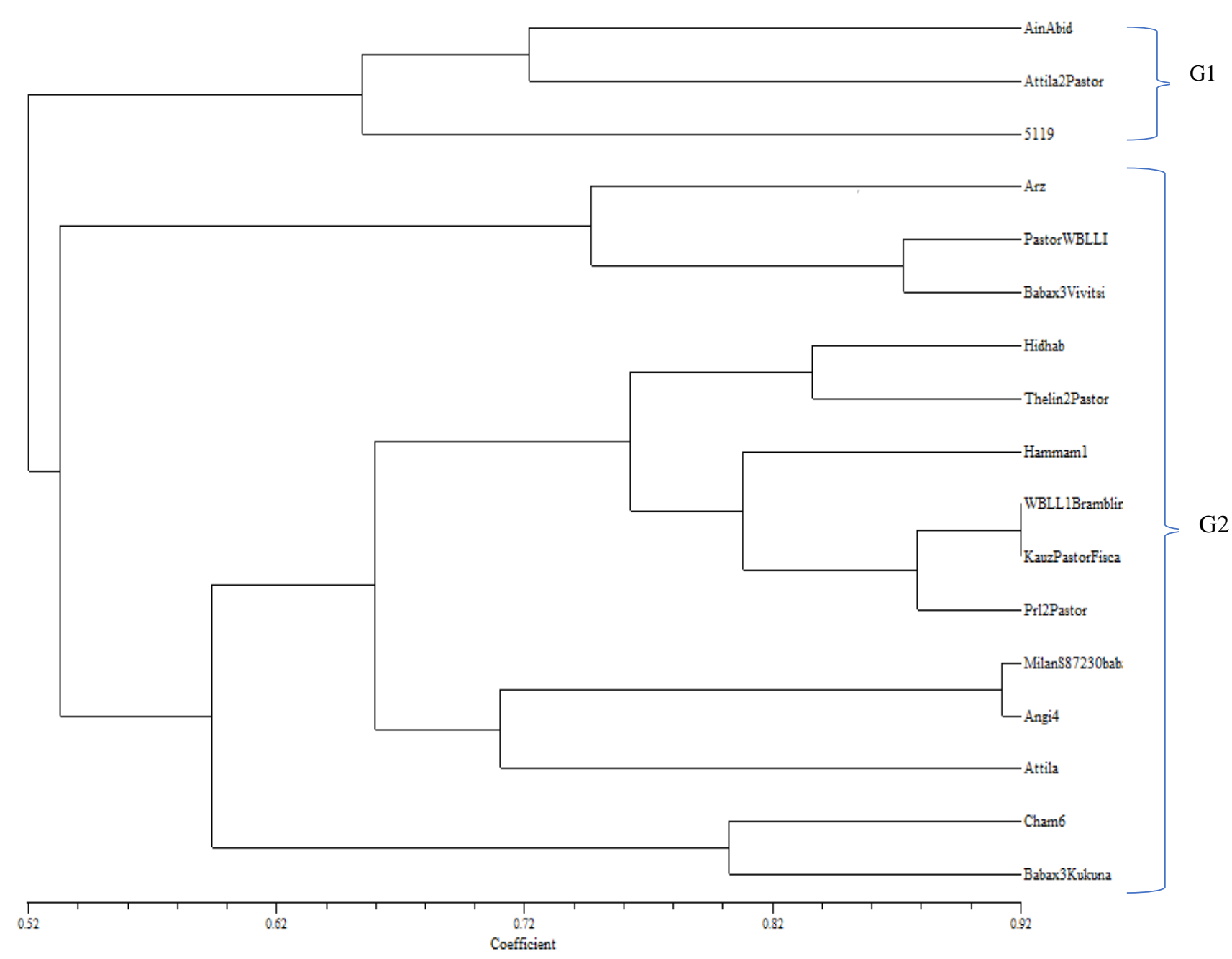

Figure 1. Dendrogram based on data of 11 microsatellite primers from 17 bread wheat genotypes constructed by UPGMA 
The higher genetic distance indicates that wheat genotypes were genetically diverse. It is an indication of their genetic dissimilarity (Kondić-Špika et al. 2016). Cluster analysis represented by a dendrogram showed that bread wheat genotypes were divided into two main clusters, the first included only three wheat genotypes Ain Abid, Attila/2 Pastor, and 5119. Kara et al. (2016) showed that these genotypes have the same agronomical characters such as lowest thousand kernels weight and number of kernels per ear. The second main cluster revealed high polymorphism and was divided into four sub-clusters (Figure 1). The first one is consists of one local genotype Arz, and two introduce one Pastor/Wbll1 and Babax/Lr42//Babax*2/3vivitsi. These genotypes showed the lowest grain yield (Kara et al. 2017). The second subcluster is composed by Hidhab (local genotype), Thelin//2*Attila*2/Pastor, Hamam 1, Wbll1*2/Brambling, Kauz/Pastor/Fiscal, Prl/2*Pastor. These are late genotypes (Kara et al. 2016). The third sub-cluster which includes Attila, Angi-4 and Milan/S87230/babax were the earliest but provide the highest grain yield and are of the same origin. The last one sub-cluster is formed by only two genotypes, i.e. cham6 and Babax/Lr42//Babax*2/3/Kukuna where showed the best agronomic characteristics (Kara et al. 2016). These results showed that not all genotypes originating from the same region clustered in the same group.

The results obtained in our study provided new information on the relationships between the bread wheat genotypes grown in Algeria. The set of the used microsatellite markers showed a high level of polymorphism and sufficient information to discriminate the cultivars of hexaploid wheat grown in Algeria. Generally, this study provides a first description of the molecular genetic diversity of Algerian and introduces bread wheat genotypes grown In Algeria. The results are in conformity with expectations and provide the first basis for further research. SSR markers successfully discriminated bread wheat cultivars. Most of the primers used in this study showed high polymorphism. The high level of genetic diversity reported in this study should be taken into account in the development of wheat breeding programs in the agro-ecological zones of Algeria. This study will constitute a platform of selection program of the most productive genotypes under Algerian condition. Morphological and phenotypic studies will also be needed to link our molecular analysis results.

These results demonstrate the reliability, usefulness, and effectiveness of microsatellites SSRs in the analysis of genomic diversity. They can be successfully employed in assaying the level of polymorphism and diversity and serves to facilitate the development of better genotypes and conservation strategies of wheat germplasm.

\section{REFERENCES}

Aissaoui MR, Fenni M. 2018. Grain yield and quality traits of bread wheat genotypes under Mediterranean Semi-arid conditions. Scholars J Agric Vet Sci 5 (3): 166-171. DOI: 10.21276/sjavs.2018.5.3.
Al Khanjari S, Hammer K, Buerkert A, Roder M. 2007. Molecular diversity of Omani wheat revealed by microsatellites. Genetic Resource Crop Evol 54: 1407-1417.

Ali Y, Atta B, Akhter J, Monneveux P, Lateef Z. 2008. Genetic variability association and diversity studies in wheat (Triticum aestivum L.) germplasm. Pak J B 40: 2087-2097.

Allahverdiyev T. 2015. Effect of drought stress on some physiological traits of durum (Triticum durum Desf.) and bread (Triticum aestivum L.) wheat genotypes. J Stress Physiol Biochem 11 (11): 29-38.

Allen AM, Winfield MO, Burridge AJ, Downie RC, Benbow HR, Barker GL, Wilkinson PA, Coghill J, Waterfall C, Davassi A, Scopes G. 2017. Characterization of a Wheat Breeders' Array suitable for highthroughput SNP genotyping of global accessions of hexaploid bread wheat (Triticum aestivum). Plant Biotechnol J 15 (3): 390-401.

Ateş Sönmezoğlu Ö, Bozmaz B, Yıldırım A, Kandemir N, Aydın N. 2012. Genetic characterization of Turkish Bread wheat landraces based on microsatellite markers and morphological characters. Turk J Biol 36: 589-597.

Ateş Sönmezoğlu Ö, Terzi B. 2018. Characterization of some bread wheat genotypes using molecular markers for drought tolerance. Physiol Mol Biol Plant 24 (1): 159-166. DOI: 10.1007/s12298-017-0492-1

Azzam CR, Abd El-Kader M H. 2010. Effect of wheat variety on protein patterns, bread and cake quality. Egypt J Plant Breed 14 (1): 135-157.

Babay E, Chaabane R, Mzid-Abdmouleh R, Ben Naceur M. 2015. Diversity of Tunisian bread wheat genotypes revealed by Morphoagronomical and microsatellite markers. Biosci J 31 (3): 701-708.

Bellatreche A, Mahdad M, Kaouadji Z, Gaouar S. 2017. Agromorphological diversity of some accessions of bread wheat (Triticum aestivum) in western Algeria. Biodiversitas 18 (1): 409-415. DOI: 10.13057/biodiv/d180153.

Bellatreche A, Mnasri S, Ben Naceur M, Gaouar SSB. 2019. Study of the Molecular Biodiversity of the Saharan Bread Wheat in Algeria. Cereal Res Comm 47: 724-739. DOI: 10.1556/0806.

Ben Naceur M. 1998. Development and assessment of new plant genotypes by molecular biology methods. Post-doctoral Graduate Report, School of Biotechnology, Korea University, Korea.

Boudour L, Gherroucha H, Boukaboub A, Bouchtab K, Baka M, Samra K. 2011. Evaluation of genetic diversity of an Algerian durum wheat (Triticum durum Desf.) collection. J Stress Physiol Biochemist 7 (3): 95-107.

CIC (Conseil International des Céréales). 2010. Les statistiques mondiales, calculées par le Conseil International des Céréales. Marché des céréales. GRM, N${ }^{\circ} .402$.

Drikvand R, Bihamta MR, Najafian G, Ebrahimi A. 2013. Investigation of genetic diversity among bread wheat cultivars (Triticum aestivum L.) using SSR Markers. J Agric Sci 5 (3): 73-97.

FAOSTAT. 2014. Statistics Division, FAOFarzad A, Mehrvar MR, Ali Nazeri A, Juraimi AS. 2013. Investigation of wheat grain quality characteristics under water deficit condition during postanthesis stage. J Agric Biol Sci 1: 273-278.

Farzad A, Mehrvar MR, Ali Nazeri A, Juraimi AS. 2013. Investigation of wheat grain quality characteristics under water deficit condition during postanthesis stage. J Agric Biol Sci 1: 273-278.

Flagella Z, Giuliani MM, Giuzio L, Volpi C, Masci S. 2010. Influence of water deficit on durum wheat storage protein composition and technological quality. Europe J Agronom 33: 197-207.

Grassini P, Eskridge KM, Cassman KG. 2013. Distinguishing between yield advances and yield plateaus in historical crop production trends. Nature Commun 4: 2918-3000.

Gultyaeva EI. 2012. Genetic diversity of Russian wheat cultivars for resistance to leaf rust. Republic Russian Academic Agric Sci 2: 29-32

Huang XQ, Börner MS, Goral MW. 2002. Assessing genetic diversity of wheat (Triticum aestivum L.) germplasm using microsatellite markers. Theoretical Appl Gen 105: 699-707.

Kara K, Brinis L. 2012. Réponse physiologique au stress hydrique de variétés de blé tendre (Triticum aestivum L.) cultivées en Algérie. Eur J Sci Res 81 (4): 524-532.

Kara K, Kanouni-Rached M, Tahar A, Brinis L. 2014. Influence of Mediterranean conditions on yield parameters and quality of breed wheat (Triticum aestivum). Intl J Adv Sci Tech Res 4 (3): 157-164.

Kara K, Mezghani N, Saddoud Debbabi O, Madini M, Ben Naceur M. 2016. Assessment of genetic diversity of wheat (Triticum aestivum L.) using agro-morphological characters and microsatellite markers. Intl J Biosci 9 (4): 92-101. DOI: 10.12692/ijb/9.4.92-101.

Kara K, Kanouni-Rached M, Saddoud Debbabi O, Ben Naceur M. 2017. Genetic diversity of bread wheat genotypes (Triticum aestivum L.) 
revealed by agromorphological characteristics and microsatellite SSR markers. Intl J Eng Res Technol 6 (1): 178- 182.

Khaled FMS, Roder MS, Borner A. 2015. Assessing genetic diversity of Egyptian hexaploid wheat (Triticum aestivum L.) using microsatellite markers. Genet Res Crop Evol 62 (3): 377-385. DOI 10.1007/s10722014-0159-5

Kondić-Špika AĐ, Denčić SS, Mladenov NV, Trkulja D, Mikić SZ, Hristov NS, Marjanović-Jeromela AM. 2016. Polymorphism of microsatellite loci in bread wheat (Triticum aestivum L.) and related species. J Nat Sci Novi Sad 131: 81-89. DOI: 10.2298/ZMSPN1631081K.

Leisova L, Kucera L, Dotlacil L. 2007. Microsatellites as tool to evaluated and characterize bread wheat core collection. Wheat Production in Stressed Environments 1: 771-778.

Malik R, Tiwari R, Arora A, Kumar P, Sheoran S. 2013. Genotypic characterization of elite Indian wheat genotypes using molecular markers and their pedigree analysis. Austr J Crop Sci 7 (5): 561-567.

Merouche A, Debaeke P, Messahel M, Kelkouli M. 2014. Response of durum wheat varieties to water in semiarid Algeria. Afr J Agric Res 9 (38): 2879-2892 DOI: 10.5897/AJAR2013.7318

Mickelbart MV, Hasegawa PM, Bailey-Serres J. 2015. Genetic mechanisms of abiotic stress tolerance that translate to crop yield stability. Nat Rev Genet 16 (4): 237-251. DOI: $10.1038 / \mathrm{nrg} 3901$

Nagy S, Poczai P, Cernák I, Gorji AM, Hegedüs G, Taller J. 2012. An online program to calculate polymorphic information content for molecular genetic studies. Biochem Genet 50 (9-10): 670-672. DOI: 10.1007/s10528-012-9509-1.

Nei M, Li WH. 1979. Mathematical model for studying genetic variation in terms of restriction endonucleases. Proc Natl Acad Sci USA 76: 5269-5273.

Ozlem AS, Begum T. 2018. Characterization of some bread wheat genotypes using molecular markers for drought tolerance. Physiol Mol Biol Plants 24 (1): 159-166.

Paux E, Sourdille P, Mackay I, Feuillet C. 2012. Sequence-based marker development in wheat: Advances and applications to breeding. Biotechnol Adv 30: 1071-1088.

Ramadugu C, Keremane ML, Hu X, Karp D, Federici CT, Kahn T, Lee RF. 2015. Genetic analysis of citron (Citrus medica L.) using simple sequence repeats and single nucleotide polymorphisms. Sci Hortic 195:124-137. DOI: 10.1016/j.scienta.2015.09.004.

Reza MD, Goodarz N, Elham Aram S. 2015. Investigation of genetic diversity of some durum and bread wheat genotypes using SSR markers. J Biodiv Environ Sci 6 (3): 24-32.
Rohlf FJ. 1989. NTSYS-pc: Numerical taxonomy and multivariate analysis system. Analysis system version 2.02, Exeter Software. Setauket, New York.

Sahnoune F, Belhamel M, Zelmat M, Kerbachi R. 2013. Climate change in Algeria: Vulnerability and strategy of mitigation and adaptation. Energy Procedia 36: 1286-1294.

Salehi M, Arzani A, Talebi M, Rokhzadi A. 2018. Genetic diversity of wheat wild relatives using SSR markers. Genetika 50: 131-141. DOI: 10.2298 / GENSR18 01131S

Salem KFM, Röder MS, Börner A. 2014. Assessing genetic diversity of Egyptian hexaploid wheat (Triticum aestivum L.) using microsatellite markers. Genet Res Crop Evol 62: 377-385. DOI 10.1007/s10722014-0159-5

Tahir NAR. 2010. Germination characteristics and molecular characterizations of some wheat varieties in Sulaimanyah by SSR marker. Turkish J Biol 34: 109-117. DOI: 10.3906/biy-0810-11.

Tékeu H, Ngonkeu E, Djocgoué F, Ellis A, Lendzemo V, Springfield L, Moulin L, Klonowska A, Diouf D, Botes W, Béna G. 2017. Genetic diversity of Cameroonian bread wheat (Triticum aestivum L.) cultivars revealed by microsatellite markers. Afr J Biotechnol 16 (36): 1832-1839. DOI: 10.5897/AJB2017.16090

Toklu F, Baloch FS, Karakoy T, Ozkan H. 2015. Effects of different priming applications on seed germination and some agromorphological characteristics of bread wheat (Triticum aestivum L.). Turk J Agric For 39: 1005-1013.

Tomar RSS, Tiwari S, Naik BK, Chand S, Deshmukh R, Mallick N, Tomar SMS. 2016. Molecular and morpho-agronomical characterization of root architecture at seedling and reproductive stages for drought tolerance in wheat. PLoS One 11 (6): 156-528. DOI: 10.1371 /journal.pone. 0156528

Yao J, Ma H, Yang X, Yao GU, Zhou M. 2014. Inheritance of grain yield and it's correlated with yield components in bread wheat (Triticum aestivum L.). Afr J Biotechnol 13 (12): 1379-1385.

Zarei Abbasabbad E, Mohammadi SA, Moghadam M, Jalal Kamali MR. 2016. Analysis of genetic diversity, population structure and linkage disequilibrium in Iranian wheat landraces using SSR markers. Plant Genet Res 15: 327-334.

Zarkti H, Ouabbo H, Hilali A, Udupa SM. 2010. Detection of genetic diversity in Moroccan durum wheat accessions using agromorphological traits and microsatellite markers. Afr J Agric Res 5: $1837-1844$ 